\title{
MRI Abnormalities Induced by Seizures
}

\author{
Nuno Canas ${ }^{1}$ and Pedro Soares ${ }^{2}$ \\ ${ }^{1}$ Neurology and Neurophisiology Departments \\ ${ }^{2}$ Neuroradiology Department, \\ Hospital Egas Moniz, \\ Institute of Pharmacology and Neurosciences, Faculty of Medicine, \\ Institute of Molecular Medicine, University of Lisbon, Lisbon, \\ Portugal
}

\section{Introduction}

When computed tomography started to be used routinely in the evaluation of patients presenting with seizures it became evident that some periictal abnormalities disappeared in follow-up studies with no specific treatment except antiepileptics. These findings suggested that those reversible abnormalities were not structural but functional, possibly resulting from the cerebral edema induced by seizure activity (Goulatia et al. 1987; Sammaritano et al., 1985; Sethi et al., 1985).

With the advent of MRI and it's increasingly use in the acute phase of seizures, these seizureinduced abnormalities were also demonstrated, being described as periictal or reversible MRI abnormalities (Cole 2004; Briellmann et al., 2005); since follow-up MRI studies disclosed that irreversible brain damage can occur in the regions previously affected by them, they are now better defined as transient periictal MRI abnormalities (TPMA). In this way, TPMA should only be considered if two conditions are fulfilled: first, the brain MRI signal abnormalities demonstrated periictally must be attributable to seizures and not other causes; and second, that these abnormalities totally or partially reverse on subsequent MRI studies. Besides the detection of TPMA, MRI can provide us with a unique non-invasive diagnostic tool to better understand the physiopathological mechanisms underlying TPMA formation, and to identify and predict the brain damage induced by seizures.

In this chapter, we review the neuroimaging features, differential diagnosis, pathophysiology, electroclinical-imagiological spectrum and outcome of TPMA, highlighting the fundamental role of multi-sequence MRI studies in their investigation.

\section{Clinical and electroencephalographic findings associated with TPMA}

TPMA have been described in several case reports (Amato et al., 2001; Bauer et al., 2006; Chu et al., 2001; Kramer et al., 1987; Senn et al., 2003) and small case series (Canas et al., 2010a; Chan et al., 1996; Huang et al., 2009; Milligan et al., 2009; Raghavendra et al., 2007), the largest not including more than 20 patients (Canas et al., 2010b). This scarcity of reports contrast with the practice of clinicians involved in the evaluation of patients presenting with seizures, where is not so uncommon to find MRI abnormalities induced by them. 
The exact incidence of TPMA is still unknown, with estimated values ranging from $0.007 \%$ (Raghavendra et al., 2007) to $29.4 \%$ (Huang et al., 2009). The best estimation of TPMA incidence that we presently have comes from a prospective study in which MRI was systematically obtained in 34 patients with status epilepticus, with TPMA being disclosed in $20.6 \%$ of them (Goyal et al., 2009). Similar TPMA incidences were reported in the studies that retrospectively reviewed the MRI obtained from patients presenting with status epilepticus, with the periictal signal abnormalities presumably attributable to seizures described in 11.6\% (Milligan et al., 2009) and 29.4\% (Huang et al., 2009) of the patients. Since these results were obtained in patients presenting with status epilepticus, a condition associated with a higher likelihood of inducing TPMA (Cole, 2004), we think that they overestimate the real TPMA incidence, a supposition supported by the much lower values described in the overall population of patients hospitalized for the evaluation of seizure disorders (Raghavendra et al., 2007).

In fact, and although TPMA have been more frequently described in convulsive status epilepticus, complex partial status epilepticus and seizures with a prominent motor component, they could be induced by virtually any type of seizure, a cluster of seizures or other forms of status epilepticus. TPMA can be disclosed in patients with presenting seizures provoked by systemic factors (such as alcohol withdrawal, infections or dialysis disequilibrium) or associated with structural cerebral pathologies, the most common being small-vessel cerebrovascular disease or post-traumatic/ post-stroke encephaloclastic lesions; and can also be demonstrated in patients with a previous history of epilepsy, often difficult to control focal symptomatic or probably symptomatic epilepsies.

The electroencephalographic findings associated with TPMA are also vary variable, with the ictal electroencephalograms generally showing focal continuous or in crescendo epileptiform discharges, rhythmic activity or lateralized periodic epileptiform discharges; in postictal electroencephalograms, the most frequent findings are focal slowing with or without associated epileptiform discharges, lateralized or bilateral periodic epileptiform discharges, frontal intermittent rhythmic delta activity, or no relevant abnormalities.

The reasons why TPMA occur in some but not all patients with seizures is still an unresolved issue. However, some critical variables have been proposed as determinants of TPMA occurrence or outcome, such as seizure type and duration, pre-existing brain lesions, pharmacological interventions (Cole, 2004) and possible hypoperfusion or hypoxia (Milligan et al., 2009). The disclosure of TPMA can also be determined by methodological factors, namely the MRI timing, with ictal or early postictal MRIs increasing the probability of their detection (Briellmann et al., 2005; Goyal et al., 2009).

\section{TPMA neuroimaging features}

TPMA may present with several MRI signal abnormalities, heterogeneous patterns and topographic distribution, contributing to wide neuroimaging features. The knowledge of these features is paramount to recognize TPMA and to make a proper differential diagnosis with other pathologies.

\subsection{Signal abnormalities}

To be visible on an MRI, the seizure-induced MRI abnormalities must be associated with a relatively widespread change in water environment (Briellmann et al., 2005). In this way, the 
intra and/ or extracellular edema induced by seizures are generally hypointense in T1weighted imaging and hyperintense in fluid-attenuated inversion recovery (FLAIR) and T2weighted imaging, with restriction to water on diffusion-weighted imaging (DWI). A pial or cortico-pial contrast enhancement can also be disclosed, particularly in larger TPMAs with a subcortical component. In the cases in which a protonic magnetic resonance spectroscopy (MRS) was obtained periictally, the most consistent findings were an increase in the lactate levels and choline and a decrease in N-acetyl-aspartate (Castillo et al., 2001; Lazeyras et al., 2000; Mueller et al., 2001), with the levels of myoinositol possibly fluctuating during and after seizures (Wellard et al., 2003). Generally, these signal abnormalities are colocalized in the same brain regions.

Although the exact mechanisms underlying these seizure-induced MRI signal changes are still not well known, some have been proposed, mostly based on theoretical models or data from experimental studies (table 1).

\begin{tabular}{|l|l|l|l|}
\hline MRI sequence & Measurement of & $\begin{array}{c}\text { Acute signal } \\
\text { change }\end{array}$ & \multicolumn{1}{|c|}{ Attributed to } \\
\hline T1-weighted & T1-signal & Increase & Cell edema \\
\hline T2-wighted & T2-signal & Increase & Cell edema \\
\hline FLAIR & FLAIR signal & Decrease & Cell edema \\
\hline \multirow{3}{*}{ DWI } & ADC & Decrease & Cytotoxic edema \\
\cline { 2 - 4 } & Lactate & Increase & Vasogenic edema \\
\cline { 2 - 4 } & N-acetyl-aspartate & Increase & Anaerobic metabolism \\
\cline { 2 - 4 } & Choline & Increase & Neuronal loss/ dysfunction \\
\cline { 2 - 4 } & Myoinositol & Decrease & Osmolyte changes \\
\hline \multirow{3}{*}{ With contrast } & $\begin{array}{l}\text { Contrast } \\
\text { enhancement }\end{array}$ & $\begin{array}{l}\text { Cortico-pial } \\
\text { enhancement }\end{array}$ & $\begin{array}{l}\text { Hypervascularization, } \\
\text { vasodilatation, breakdown of the } \\
\text { blood-brain barrier }\end{array}$ \\
\hline
\end{tabular}

Table 1. MRI signal abnormalities induced by seizures.

Several authors highlighted the prominent role of DWI in disclosing TPMA (Kim et al., 2001; Szabo et al., 2005). DWI is the most sensitive MRI-sequence in detecting TPMA (restriction to water diffusion present in more than $90 \%$ of the cases), being frequently the only reliable signal abnormality in small TPMAs restricted to the cerebral cortex or in TPMAs bordering old encephaloclastic lesions (Canas et al., 2010b). In the cases in which attenuation diffusion coefficient (ADC) studies were obtained, some authors reported an increased DWI signal with decreased diffusivity, compatible with cytotoxic edema (Chu et al., 2001; Parmar et al., 2006; Szabo et al., 2005), and others a decreased DWI signal with increased diffusivity, disclosing vasogenic edema (Hong et al., 2004; Wieshmann et al., 1997); other authors, including ourselves, described diverse findings in the TPMA ADC studies, with some 
patients showing a predominantly cytotoxic or vasogenic edema, while others having intermixed areas of both types of edema, mainly cortical cytotoxic edema and subcortical vasogenic edema (Canas et al., 2010a, 2010b; Kim et al., 2001).

The timing of MRI acquisition has been proposed by some authors as one of the factors that could contribute to these apparently non-congruent findings regarding the TPMA ADC signal abnormalities (Briellmann et al., 2005; Hong et al., 2004). Animal experiments disclosed that, early after a seizure, the lactate levels increase and the ADC values decrease, with these changes attributed to the failure of the $\mathrm{Na}^{+} / \mathrm{K}^{+}$-ATPase pump and anaerobic metabolism (Najm et al., 1997; Righini et al., 1994; Wang et al., 1996); whereas the lactate changes are short-lived, the ADC value is maximally decreased at 24 hours, returning to the control level or increasing in the following 48 to 72 hours, when T2-weighted abnormalities emerge (Nakasu et al., 1995; Righini et al., 1994). However, in clinical practice we can observe different MRI signal abnormalities, including increases and decreases in ADC values, in MRIs performed with similar timings regarding the seizure onset, disclosing that other factors must be considered. We believe that one of those factors is the diverse susceptibilities of different brain regions to the pathophysiological mechanisms involved in TPMA formation (see below).

\subsection{Topography and patterns}

The great majority of TPMAs are focal and unilateral, cortically restricted or with a corticosubcortical pattern. Although they can arise anywhere in the cerebral neocortex, they are commonly disclosed in the posterior and perirolandic regions or in the periphery of old encephaloclastic lesions (Silverstein \& Alexander, 1998; Canas et al., 2010b). Less frequently they have a marked subcortical component, with mass effect and gyral effacement, mimicking an intracerebral neoplasm (Canas et al., 2010a; Cohen-Gadol et al., 2004; Hicdonmez et al., 2003); are more diffuse or bilateral; or are associated with remote signal abnormalities, affecting structures anatomically distant from the neocortical seizure focus, including the contralateral cerebellar hemisphere (cerebellar diaschisis), thalamus (more frequently the pulvinar), splenium of the corpus callosum, caudate and globus pallidus (Cole, 2004). In some cases, evanescent T2-weighted and DWI abnormalities are disclosed in cortical regions widely separated from the probable seizure focus, with the signal abnormalities of these migratory lesions and TPMA resolving almost simultaneously (Cole, 2004; Raghavendra et al., 2007). Remote and migratory signal abnormalities are believed to result from seizure propagation through neuronal pathways, and are usually associated with larger neocortical TPMA.

\subsection{Classification}

The first classification for TPMA was proposed by Cole, who classified them into local (colocalized with the epileptic discharge) and remote (affecting distant structures) (Cole, 2004). After that, two comprehensive classification systems to cover the broad spectrum of changes that comprise TPMA were proposed by us (Canas et al., 2010b) and other authors (Raghavendra et al., 2007). These two classifications are based mostly on TPMA patterns and signal abnormalities, facilitating their recognition by Neurologist and Neuroradiologists, and helping in their differential diagnosis.

Raghavendra and colleagues classified TPMA into type I, restricted to the superficial gray matter; type II, affecting the superficial gray and subcortical white matter (type IIa) or with 
the subcortical white matter involvement extending to the adjacent periventricular surface (type IIb); type III, with involvement of the subcortical nuclei associated with any degree of cortical or white matter involvement; type IV, involvement of white matter alone; and type $\mathrm{V}$, with leptomeningeal enhancement and/ or gyriform cortical enhancement. Regarding the differential diagnosis, type I and IIa can mimic encephalitis, type IIb an intracerebral neoplasm and type $\mathrm{V}$, due to the leptomeningeal involvement, meningoencephalitis; type IV can mimic several pathologies and in type $\mathrm{V}$ the ictal onset may have a poor localizing value (Raghavendra et al., 2007).

Our classification has several similarities to the classification proposed by Raghavendra and colleagues (Raghavendra et al., 2007), although we did not find any TPMA restricted to the subcortical white matter (Canas et al., 2010b). We classified TPMA into type 1, restricted to the cerebral cortex, and type 2, cortico-subcortical. Type 2 TPMA can further have a marked subcortical component with mass effect, mimicking a tumor lesion (type 2A- tumor-like); be in the periphery/ bordering an old encephaloclastic lesion (type $2 \mathrm{~B}$ ) or be associated with remote signal abnormalities (type 2C) (table 2).

\begin{tabular}{|c|c|c|c|}
\hline Type & Characteristics & Main MRI features & Major differential diagnosis \\
\hline 1 & Cortically restricted & $\begin{array}{l}\text { Frequently only disclosed } \\
\text { on DWI }\end{array}$ & $\begin{array}{l}\text { Small embolic stroke } \\
\text { Creutzfeldt-Jacob disease }\end{array}$ \\
\hline 2 & Cortico-subcortical & $\begin{array}{l}\text { Any of the TPMA signal } \\
\text { abnormalities }\end{array}$ & $\begin{array}{l}\text { Embolic stroke, Encephalitis, } \\
\text { meningoencephalitis, venous } \\
\text { thrombosis, }\end{array}$ \\
\hline $2 \mathrm{~A}$ & $\begin{array}{l}\text { Prominent } \\
\text { subcortical } \\
\text { component }\end{array}$ & $\begin{array}{l}\text { Mass effect, frequent } \\
\text { contrast enhancement; } \\
\text { marked vasogenic edema }\end{array}$ & $\begin{array}{l}\text { Intracerebral neoplasm, low } \\
\text { grade gliomas }\end{array}$ \\
\hline $2 \mathrm{~B}$ & $\begin{array}{l}\text { Bordering an old } \\
\text { encephaloclastic } \\
\text { lesion }\end{array}$ & $\begin{array}{l}\text { Frequently only disclosed } \\
\text { on DWI }\end{array}$ & Small embolic stroke \\
\hline $2 \mathrm{C}$ & $\begin{array}{l}\text { Associated with } \\
\text { remote lesions }\end{array}$ & $\begin{array}{l}\text { Signal abnormalities in the } \\
\text { contralateral cerebellum, } \\
\text { or the homolateral } \\
\text { pulvinar, caudate, } \\
\text { pallidus }\end{array}$ & $\begin{array}{l}\text { Reversible posterior } \\
\text { leukoencephalopathy } \\
\text { syndrome, stroke, } \\
\text { Creutzfeldt-Jacob disease }\end{array}$ \\
\hline
\end{tabular}

Table 2. Proposed TPMA classification

Topographically, the great majority of type 1, type 2A and 2B TPMA are focal and unilateral, while most type $2 \mathrm{C}$ are larger (hemispheric, lobar, multilobar) and/ or bilateral. Tumor-like TPMA are frequently disclosed in patients with presenting seizures without a known etiology and generally are associated with a good outcome (Canas et al., 2010a); conversely, type $2 \mathrm{C}$ generally occur in patients with a previous history of epilepsy, and are associated with a high percentage of clinical and MRI sequelae (Canas et al., 2010b). The factors predisposing patients with similar types and duration of seizures to develop different types of TPMA remain to be elucidated. 
The wide spectrum of TPMA signal abnormalities, topography and patterns are shown in figures 1 to 7 . To better understand our proposed TPMA classification, a clinical vignette is provided, including the outcome of the disclosed TPMA.
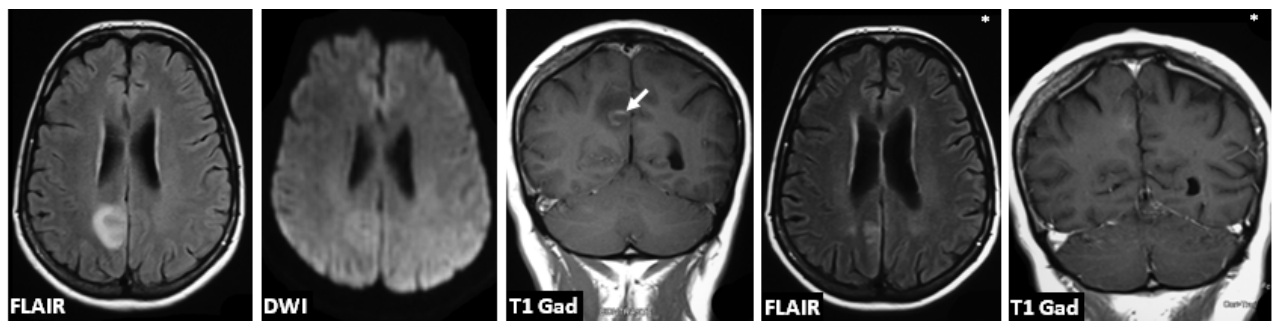

Fig. 1.56 year-old female patient with 3 left focal motor seizures in 1 hour, one with secondarily generalization; there was no history of epilepsy and the seizure etiology was undetermined. The periictal MRI disclosed a pseudotumoral lesion (type 2A TPMA) around the right marginal sulcus, hyperintense on FLAIR, hypointense on T1 and with a cortico-pial pattern of gadolinium (Gad) enhancement (arrow). There was no significant diffusion restriction, thus suggesting vasogenic edema. $\left(^{*}\right)$ The follow-up MRI at 2 months showed resolution of the edema and contrast enhancement, with cortical laminar necrosis in the previously affected region; in spite of this, there were no clinical or electroencephalographic sequels.
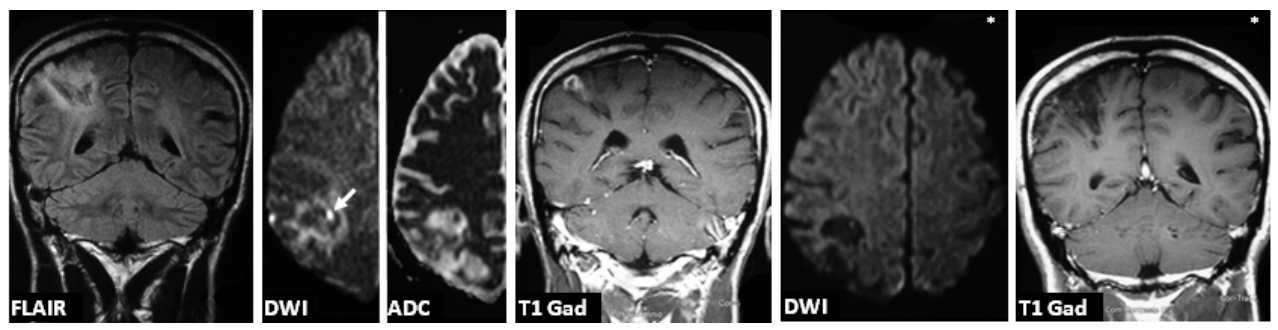

Fig. 2. 45 year-old male patient, with two simple motor seizures affecting the left arm, one with secondarily generalization; he had a left hemiparesis due to previous stroke, but no history of epilepsy; the presenting seizures were induced by alcohol withdrawal. The periictal MRI disclosed an old right parietal ischemic stroke, surrounded by focal diffusion restriction (arrow), gadolinium (Gad) enhancement and FLAIR hyperintensity (type 2B TPMA), attributable to acute seizures and not to a new small embolic stroke. $\left(^{*}\right)$ The followup MRI at 3 months showed resolution of the periictal signal abnormalities, although the patient developed de novo focal epilepsy and aggravated the pre-existing left hemiparesis. 

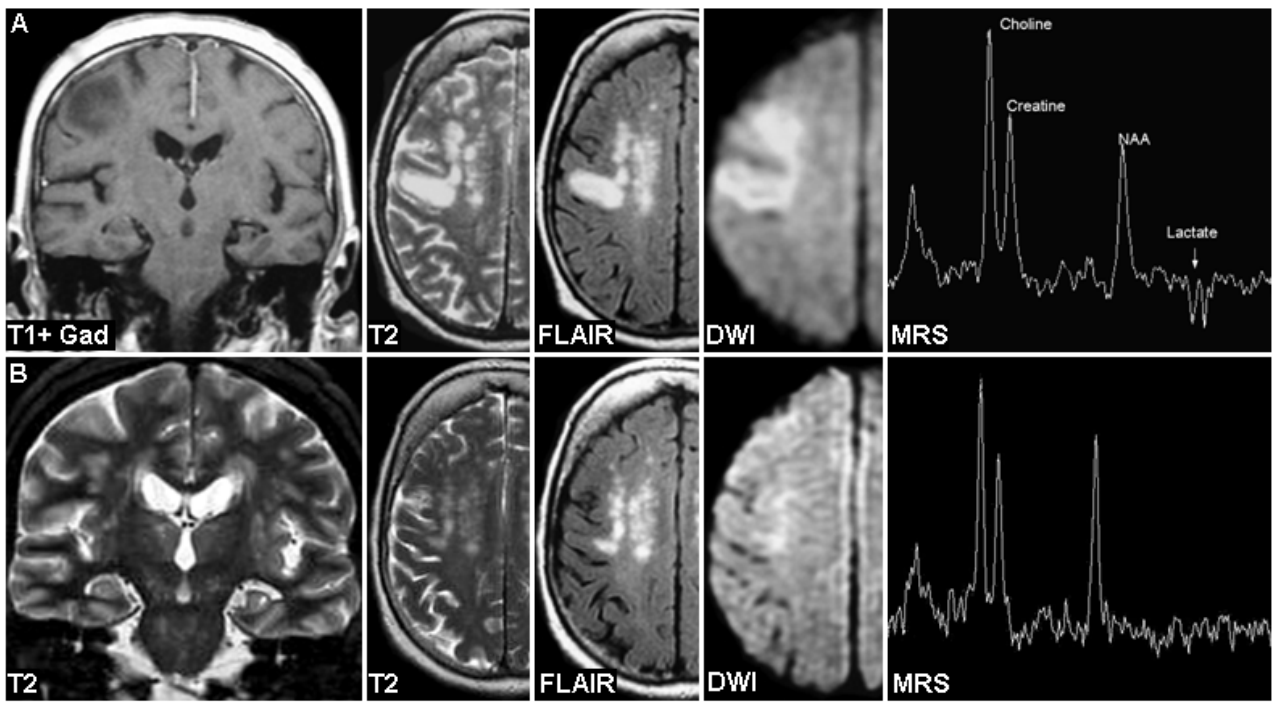

Fig. 3. 73 year-old female patient presenting almost continuous clonic jerks of the left hemiface in the last 5 days; the etiology of the simple motor status epilepticus was attributed to small-vessel cerebrovascular disease. The periictal MRI disclosed a hyperintensity of the right precentral gyrus with subcortical involvement and mass effect on T2 and FLAIR, a T1weighted hypointensity, DWI restriction and no contrast enhancement; lesional MRS revealed a decrease in N-acetyl-aspartate (NAA) and an inverted lactate peak (type 2A TPMA). The Follow-up MRI after 60 months (B) shows resolution of the precentral signal abnormalities, with slight regional brain atrophy, mild recovery of the choline / N-Acetyl A ratio and lactate normalization on MRS. In spite of these residual MRI findings, there were no clinical or electroencephalographic sequels attributable to the TPMA.
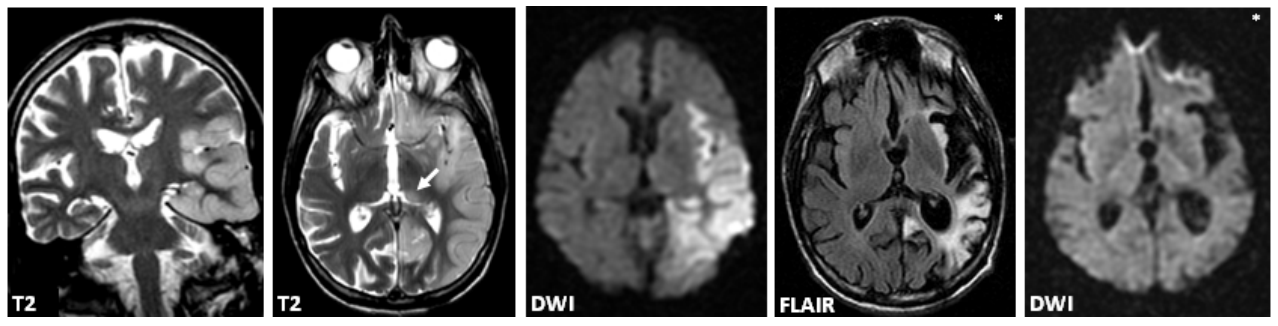

Fig. 4.45 year-old male patient with consciousness impairment in the last 6 hours. The ictal electroencephalogram showed continuous epileptiform discharges over the left temporal region, diagnosing complex partial status epilepticus, attributed to alcohol withdrawal. The periictal MRI disclosed diffuse left hemisphere cortical swelling, T2 hyperintensity and diffusion restriction, associated with remote left pulvinar (arrow) T2 and DWI hyperintensity (type 2C TPMA). (*) The follow-up MRI at 5 months showed resolution of diffusion restriction signal abnormalities and edema, with marked focal atrophy and cortical-subcortical gliosis. The irreversible brain damage that resulted from the TPMA was responsible for Wernicke aphasia and de novo focal symptomatic epilepsy. 

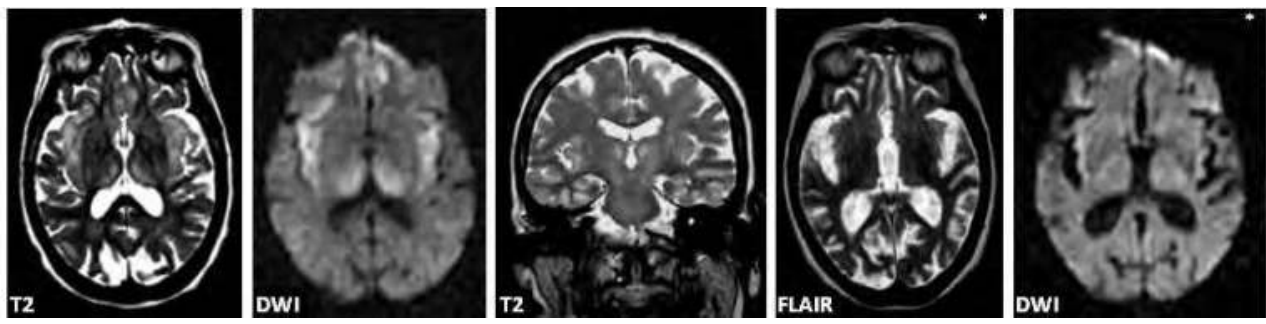

Fig. 5.59 year-old female patient with a previous history of post-stroke epilepsy. In the last 3 days she presented with stupor, with occasional nystagmoid eye jerks. The ictal EEG allowed the diagnosis of subtle status epilepticus, attributed to a change in the usual antiepileptic medication. The periictal MRI showed bilateral cortico-subcortical T2 and DWI hyperintensities involving the insula, frontal and temporal lobes, the cingulum, the hippocampus and the pulvinar (type 2C TPMA). (*) The follow-up MRI at 3 months showed resolution of diffusion restriction signal abnormalities and aggravation of the diffuse cerebral atrophy. After the status epilepticus control, the patient remained tetraparetic and died after 5 months.
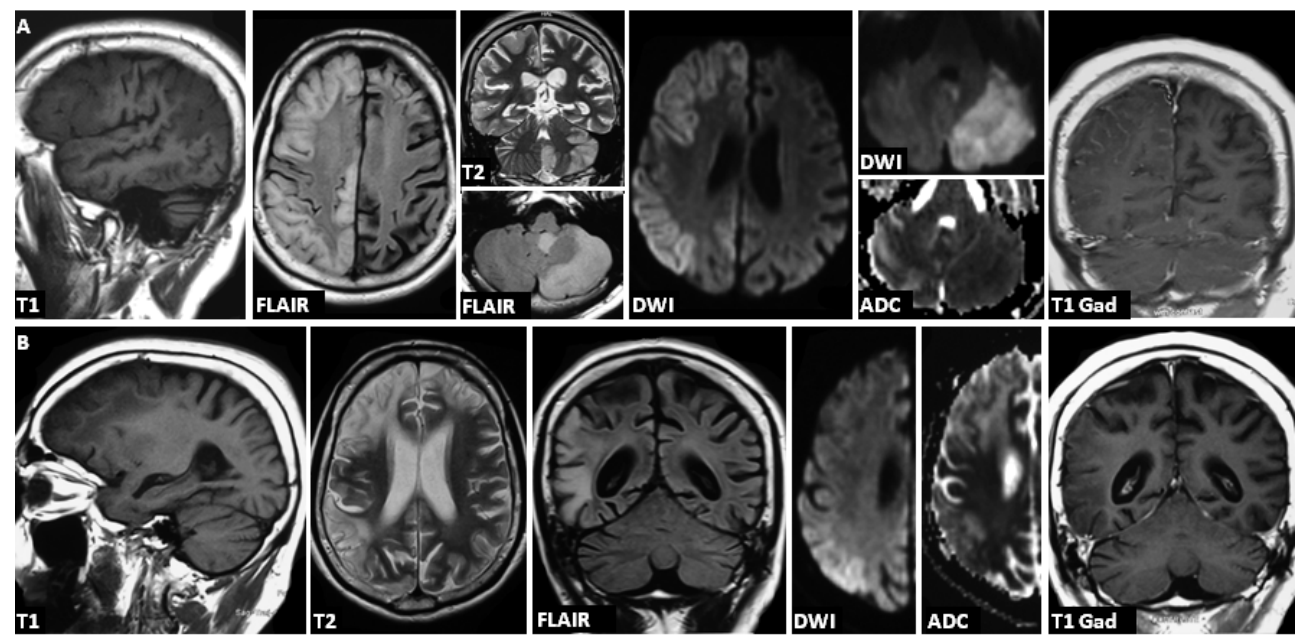

Fig. 6. 35 year-old male patient with cryptogenic refractory temporal lobe epilepsy.

Consciousness impairment with occasional clonic jerks of the left arm in the last 2 days, with the ictal electroencephalogram diagnosing complex partial status epilepticus. The periictal MRI disclosed cortical-subcortical edema and signal changes of the entire right cerebral hemisphere, sparing the rolandic area, with cortical diffusion restriction and cortico-pial contrast enhancement; concomitant contra-lateral cerebellar hemisphere and tonsil signal changes (crossed cerebellar diaschisis) (type 2C TPMA). ( ${ }^{*}$ ) The follow-up MRI at 5 months showed resolution of the edema and contrast enhancement, with cortico-subcortical $\mathrm{T} 2$ and FLAIR hyperintensities in the previously affected areas (demyelination and gliosis), and generalized brain atrophy, more marked at the right frontal lobe. After the status epilepticus, the patient developed a left hemiparesis. 

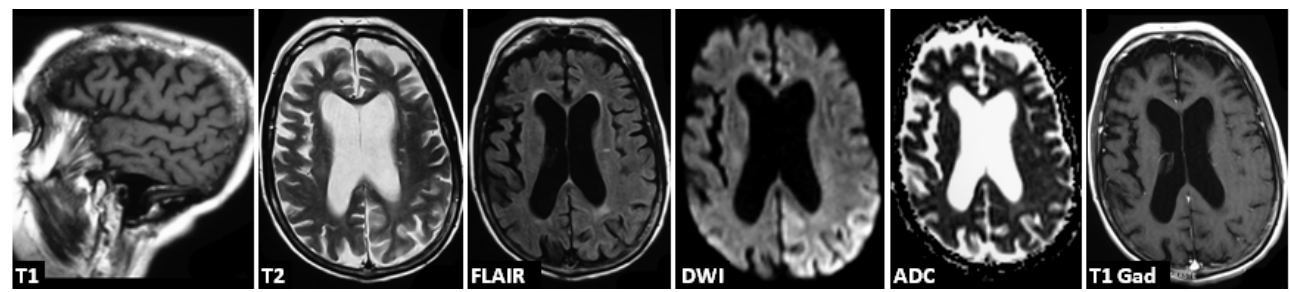

Fig. 7.78 year-old female patient with a previous history of hypertension and diabetes mellitus type II. Admitted with consciousness impairment and occasional jerks of the right arm in the last 3 days; the ictal electroencephalogram disclosed periodic lateralized epileptiform discharges with a higher amplitude over the left posterior regions; the diagnosis of complex partial status epilepticus was admitted, attributable to small-vessel cerebrovascular disease. The periictal MRI disclosed left parieto-occipital cortical diffusion restriction without significant signal changes in the other sequences (type 1 TPMA), which disappeared in follow-up MRIs. After few months, the patient developed de novo partial epilepsy easily controlled with antiepileptics.

\subsection{Differential diagnosis}

The difficult differential diagnosis between the lesions induced by seizures and other pathologies as been described since the earlier computed tomography descriptions (Silverstein \& Alexander, 1998). In the MRI era those difficulties persisted, mostly due to the similar signal abnormalities disclosed on focal TPMA and other pathologies that may present with seizures, namely acute ischemic stroke, intracerebral tumors, reversible posterior leukoencephalopathy syndrome, encephalitis, and venous infarctions resulting from cerebral venous thrombosis.

The differential diagnosis with all these pathologies is particularly relevant in a patient with a first seizure or presenting SE since the attending clinicians may assume that the observed MRI abnormalities are the cause and not the consequence of seizures, a supposition that may possibly lead to unnecessary diagnostic procedures. Although the clinical context in which seizures occur is fundamental to make a correct diagnosis, certain particularities resulting from a detailed MRI evaluation can also contribute for that.

The differential diagnosis of TPMA with embolic acute stroke is mostly relevant, since both situations occur with a prominent cortico-subcortical water restriction on DWI studies. However, TPMA generally do not respect vascular territories, such as in acute stroke (Lansberg et al., 1999), and in uncertain cases a hyperperfusion demonstrated on perfusion computed tomography (Masterson et al., 2009) or MRI (Flacke et al., 2000; Szabo et al., 2005) favors TPMA, while hypoperfusion favors stroke. Other relevant differential diagnosis of TPMA, namely if they have a tumor-like appearance, is with low grade gliomas; in this situation, the results of the DWI studies are very helpful, with TPMA having a marked restriction to water diffusion, generally not present in low grade gliomas (Cha, 2006). Regarding encephalitis and venous infarctions resulting from cerebral venous thrombosis the differential diagnosis with TPMA can only be properly made after the CSF analysis and venous angiography, respectively, excluded these pathologies. The patterns and signal abnormalities of TPMA are so similar to the ones observed in reversible posterior leukoencephalopathy syndrome that solely the clinical context in which they occur can help to make a proper differential diagnosis (Hinchey et al., 1996; Kozak et al., 2007). The same 
applies to TPMA restricted to the cerebral cortex or associated with remote lesions, very similar to the MRI abnormalities observed in Creutzfeldt-Jacob disease (Meissner et al., 2008; Young et al., 2005).

We must highlight that in some cases, and in spite of a detailed clinical history and MRI analysis, the differential diagnosis between TPMA and some of these pathologies can be very difficult. In these situations, the results of subsequent neuroimaging studies obtained some days after seizure control can be very helpful, with the disappearance of the abnormalities strongly favoring the diagnosis of TPMA.

\section{TPMA electroclinical-imagiological spectrum}

Although a high topographic concordance between the clinical, electroencephalographic and MRI findings have been described in most case reports, only recently large case series applied systematically these studies to determine the electroclinical-imagiological spectrum of TPMA. In a recent case series, Huang and colleagues reported an almost complete topographic concordance between the periictal MRI abnormalities and the electroclinical findings in 15 patients presenting with status epilepticus (Huang et al., 2009); similar findings were described in 10 patients with partial status epilepticus, with the periictal DWI abnormalities always colocalized with the ictal electroencephalographic activity disclosed on video-EEG (Di Bonaventura et al., 2009).

In more heterogeneous case series, including patients with different types of seizures and status epilepticus, the degree of this concordance is significantly lower: in 12 patients with a single or a cluster of focal seizures with or without secondarily generalization, Raghavendra and colleagues described a 75\% topographic concordance between reversible periictal MRI abnormalities and the electroclinical findings (Raghavendra et al., 2007); and in our own case series, using more strict topographic criteria, this concordance was only observed in 7 out of 19 patients, with the others presenting several possible combinations between the clinical, MRI and electroencephalographic data: TPMA colocalized with electroencephalographic findings, with patients presenting generalized seizures; partial seizures concordant with focal electroencephalographic findings, with more widespread TPMA; partial seizures concordant with TPMA, with the electroencephalogram showing more diffuse abnormalities; focal TPMA, generalized seizures, and non-focal electroencephalographic abnormalities; colocalized electroencephalographic and clinical findings with "mirror-like" TPMA; and bilateral TPMA associated with diffuse electroencephalographic findings and generalized seizures (Canas et al., 2010b).

The broad electroclinical-imagiological spectrum that we and others describe can be mostly attributed to methodological and clinical factors (table 3). The degree of homogeneity of the clinical, imagiological and electroencephalographic data included for analysis seems to be a determinant methodological factor, with the inclusion of patients of different types of seizures/ status epilepticus and wide timings of MRI and electroencephalographic studies contributing to a lower level of concordance; conversely, a better concordance is associated with a short time-lag between the acquisition of these studies (figure 8) (Cole, 2004; Goyal et al., 2009; Huang et al., 2009). The topographic criteria used for concordance is also very relevant, with more broad criteria, considering concordant electroencephalographic and MRI findings lateralized to the probable seizure focus or admitting generalized seizures associated with focal MRI and electroencephalographic findings as probably generalized, increasing its level (Canas et al., 2010b). Sustained and prolonged focal seizures are also 
highly colocalized with the MRI and electroencephalographic findings (figure 9) (Cole, 2004; Goyal et al., 2009; Huang et al., 2009), in opposition to a systemic seizure etiology, mostly due to its possible associated diffuse electroencephalographic abnormalities (Canas et al., 2010).

\begin{tabular}{|l|l|}
\hline \multicolumn{1}{|c|}{ Methodological } & \multicolumn{1}{c|}{ Clinical } \\
\hline Homogeneity of the analyzed data & Seizure type and duration \\
\hline Time-lag between studies & Seizure etiology \\
\hline Criteria for topographic concordance & Seizure dynamics \\
\hline
\end{tabular}

Table 3. Factors affecting the TPMA electroclinical-imagiological spectrum
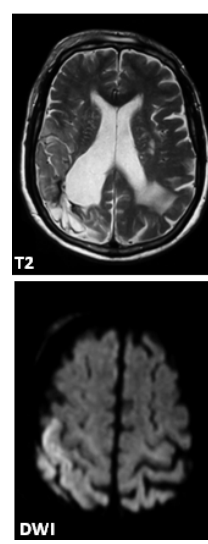
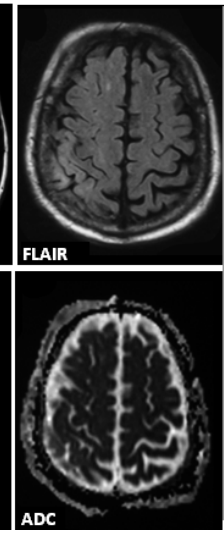

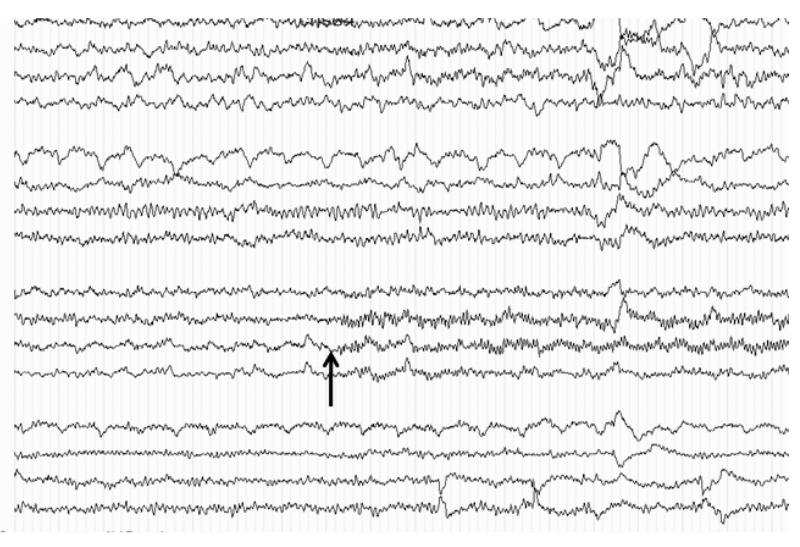

Fig. 8. 67 year-old male patient with post-stroke epilepsy. Hospitalized with recurrent motor seizures of the left-hemibody in the last 7 hours, triggered by low antiepileptic levels. The periictal MRI, obtained within 24 hours after seizure control, disclosed a DWI restriction in the periphery of an old encephaloclastic lesion (type 2B TPMA), which reversed on subsequent studies; the ictal electroencephalogram revealed a seizure-onset in right central region, characterized by rhythmic fast activity (arrow). The short time-lag between studies (ictal electroencephalogram, early postictal MRI) certainly contributed to the excellent electroclinical-imagiological topographic concordance observed in this case.

Another factor that must be considered in the evaluation of the TPMA electroclinicalimagiological spectrum is seizure dynamics. In fact, the rapid seizure propagation from a epileptic focus can contribute for the apparently non-concordant topographic findings that we described (Canas et al., 2010b): in patients presenting generalized seizures with focal colocalized electroencephalographic and MRI findings, the seizures most probably propagated from a epileptic focus defined by the results of those two exams, an hypothesis particularly conceivable in patients presenting structural cerebral abnormalities; when focal concordant clinical and electroencephalographic findings are associated with more widespread MRI abnormalities, the seizure focus is probably defined according to electroclinical criteria, with the more extensive TPMA resulting from the seizure propagation through neuronal pathways; and when the patients present partial seizures concordant with focal TPMA, with electroencephalograms showing more diffuse 
abnormalities (namely periodic lateralized or bilateral epileptiform discharges), the seizure focus is probably defined according to clinical and MRI criteria. The same seizure dynamics probably also justifies all cases of TPMA associated with remote or migratory signal changes and the cases with "mirror-like" TPMA. The determinant role of seizure dynamics to the electroclinical-imagiological spectrum of TPMA was also previously highlighted by other authors (Cole et al., 2004; Goyal et al, 2009).
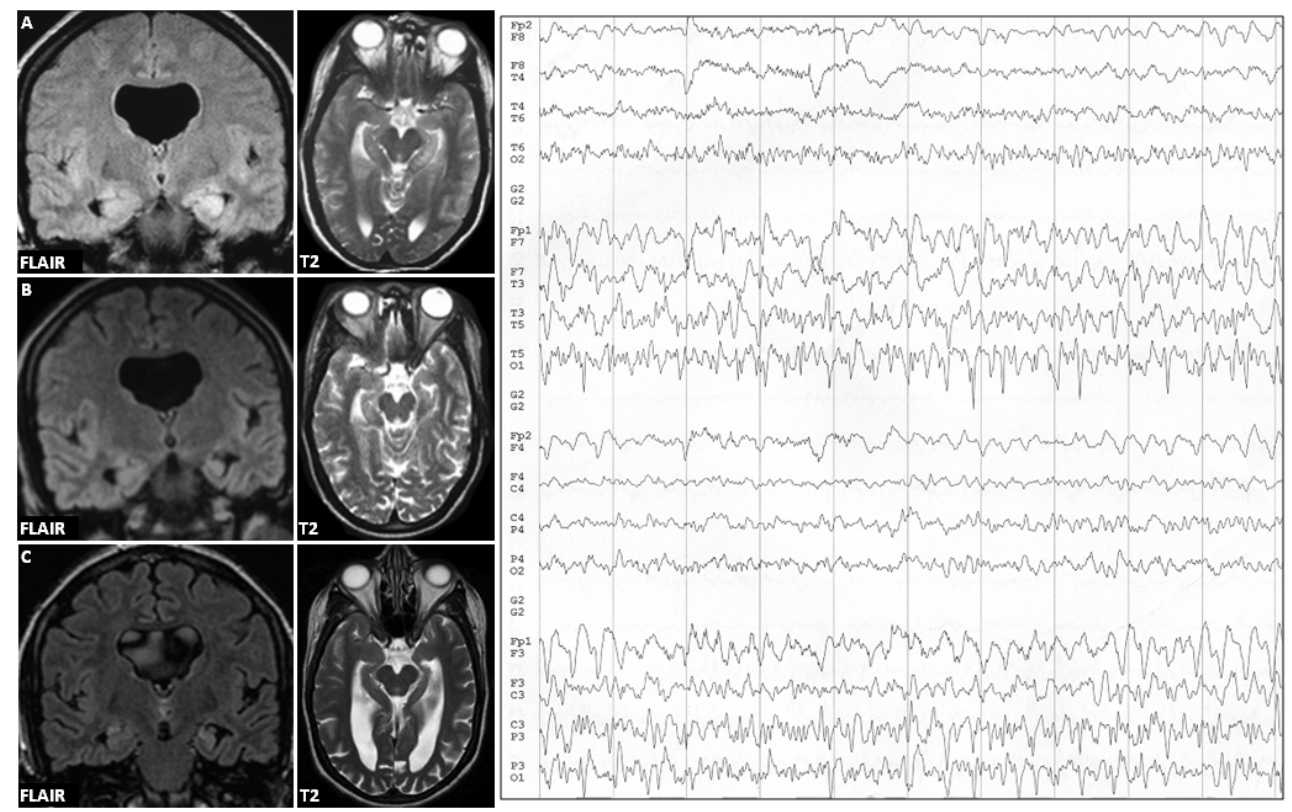

Fig. 9. 23 year-old female patient admitted with behavior abnormalities in the last 3 days. The ictal electroencephalogram showed slowing of the background activity over the left hemisphere and continuous spikes and sharp-waves over the left temporal region, compatible with complex partial status epilepticus. The periictal MRI (A), obtained 4 days after seizure control, disclosed swelling of the left hippocampal formation, with cortical hyperintensity on FLAIR and T2-weighted images (Type 1 TPMA); constitutional alterations of the brain are also seen, being the probable cause of the presenting status epilepticus. After 5 months (B), the follow-up MRI showed reversion of the signal abnormalities; and after 19 months (C) atrophy of the left hippocampus, with mild hyperintensity on T2 and FLAIR, suggestive of hippocampal sclerosis. In this case, in spite of a late periictal MRI, the sustained and prolonged status epilepticus contributed to the topographic concordance between the clinical, electroencephalographic and MRI findings.

\section{TPMA outcome}

In follow-up studies, the periictal MRI abnormalities attributable to seizures may totally reverse or induce irreversible brain damage. In this last situation, focal cortical laminar necrosis, T2 and/or FLAIR hyperintensities, atrophy and a decrease in N-acetyl-aspartate may be observed in the regions previously affected by TPMA, disclosing gliosis and 
neuronal loss (Briellmann et al., 2002, 2005). These focal changes will eventually lead to a new seizure focus and the development of the novo focal epilepsy (Bartolomei et al., 1996; Parmar et al., 2006) or may coexist without any clinical or electroencephalographic evidence of chronic epilepsy (Chu et al., 2001; Senn et al., 2003). In our own series, we found an high incidence $(63.2 \%)$ of clinical, MRI and electroencephalographic sequelae attributable to TPMA, with only small TPMA induced by systemic factors or tumor-like TPMA associated with a better outcome (Canas et al., 2010b); these TPMA sequelae were not only showed in patients with presenting seizures, but also in epileptic patients, with the appearance or aggravation of focal neurological deficits. However, we recognized that some confounding factors could have influenced our results, namely the high incidence of the novo epilepsy in patients with presenting seizure associated with structural brain lesions (small-vessel cerebrovascular disease, old encephaloclastic lesions), possibly the first seizures of a focal symptomatic epilepsy.

At the periictal phase there are some TPMA characteristics that can help to predict their outcome. One of the most relevant is the type of edema disclosed on the DWI/ ADC studies: if TPMA are mainly composed of cytotoxic edema, the probability of inducing irreversible brain damage is higher, with the consequent topographically concordant clinical and electroencephalographic sequels (Canas et al., 2010b; Parmar et al., 2006); on the contrary, the TPMA mainly composed by vasogenic edema partially or totally reverse without any clinical or electroencephalographic consequence (Cohen-Gadol et al., 2004; Raghavendra et al., 2007; Canas et al., 2010a). TPMA affecting the temporal lobe, and particularly the mesial structures (hippocampus and amygdala) may also be associated with a worse outcome, possibly leading to the development of hippocampal sclerosis and the appearance of the novo epilepsy (Bartolomei et al., 1998; Juhazc et al., 1998; see also figure 9). The vulnerability of the temporal structures to seizures was demonstrated in the neuropathological analysis of patients dying from status epilepticus, with a substantial cell loss and gliosis in the hippocampus (Nixon et al., 2001; Pohlmann-Eden et al., 2006); some MRI signal abnormalities have been associated with the development of permanent hippocampal damage, mainly the presence of periictal cytotoxic edema and a lactate peak on protonic

\begin{tabular}{|l|l|l|l|}
\hline \multicolumn{1}{|c|}{ Analyzed data } & \multicolumn{1}{|c|}{ Analysis of } & \multicolumn{1}{c|}{ Worse outcome } & \multicolumn{1}{|c|}{ Better outcome } \\
\hline \multirow{4}{*}{$\begin{array}{l}\text { TPMA } \\
\text { characteristics }\end{array}$} & $\begin{array}{l}\text { Predominant type of } \\
\text { edema }\end{array}$ & Cytotoxic & Vasogenic \\
\cline { 2 - 4 } & Location & Temporal & Extra-temporal \\
\cline { 2 - 4 } & Size & $\begin{array}{l}\text { Large cortico- } \\
\text { subcortical }\end{array}$ & $\begin{array}{l}\text { Small cortically } \\
\text { restricted }\end{array}$ \\
\cline { 2 - 4 } & Type & Type 2B, type 2C & Type 2A (tumor-like) \\
\hline \multirow{4}{*}{ Other MRI } & $\begin{array}{l}\text { Associated structural } \\
\text { cerebral disease }\end{array}$ & Yes & No \\
\hline \multirow{4}{*}{ Clinical } & Type of seizures & $\begin{array}{l}\text { Status epilepticus, } \\
\text { convulsive }\end{array}$ & $\begin{array}{l}\text { Single/ short } \\
\text { seizures, non- } \\
\text { convulsive }\end{array}$ \\
\cline { 2 - 4 } & $\begin{array}{l}\text { Etiology of presenting } \\
\text { seizures }\end{array}$ & $\begin{array}{l}\text { Structural cerebral } \\
\text { disease }\end{array}$ & Systemic factors \\
\cline { 2 - 4 } & Preexisting epilepsy & Yes & No \\
\hline
\end{tabular}

Table 4. Proposed factors that may help to predict the TPMA outcome 
MRS (Farina et al., 2004; Parmar et al., 2006), and a T2-weighted hyperintensity in the days following seizures (Provenzale et al., 2008). Finally, we demonstrated that the type of TPMA could help to predict their outcome, with large TPMA associated with remote lesions (type 2C), TPMA in the periphery of cortical lesions (type 2C) and TPMA disclosed in patients with presenting seizures attributed to cerebral brain lesions associated with a higher likelihood of clinical, MRI and electroencephalographic sequels (Canas et al., 2010b).

Based on the available literature and in our own experience, we propose the integrated analysis of some data for the prediction of TPMA outcome. These data, besides including the TPMA neuroimaging features, also consider other clinical and MRI findings (table 4).

\section{Pathophysiological mechanisms underlying TPMA formation and outcome}

Although the exact pathophysiological mechanisms underlying the seizure-induced MRI abnormalities are still not completely elucidated, the results of animal experiments and clinical observations obtained over the last years lead to a conceptual hypothesis, first proposed be Cole (Cole, 2004), and after supported by us and other authors (Canas et al., $2010 \mathrm{~b})$. This hypothesis is based mostly on the capacity of certain brain regions to deal with the perfusion and energy demands triggered by seizure activity, which is determined by their intrinsic threshold; these hypothetical mechanisms, besides explaining some of the periictal MRI changes, could also help to clarify the TPMA electroclinical-imagiological spectrum, outcome, and some apparently contradictory findings described in the literature. The cortical hyperemia associated with provoked or spontaneous seizures is a common finding reported by neurosurgeons. Non-invasive methods, such as single-photon emission computed tomography, positron emission tomography, intracranial doppler and MRangiography, also disclosed that focal seizures are associated with high metabolic demands and a marked blood flow increase to the seizure focus (Juhazc et al., 1998; Theodore, 1999; Doherty et al., 2004). The corresponding hyperperfusion may disrupt the blood-brain barrier and justify the vasogenic edema and contrast enhancement observed in some cases (Wieshmann et al., 1997; Hong et al. 2004); that is supported by the prominent vascular congestion and perivascular hemosiderin deposition that was demonstrated in the rare cases of tumor-like TPMA that were biopsied (McClelland et al., 2005). When this increase in blood flow fails to compensate the focal glucose hypermetabolism, anaerobic metabolism takes place, with the released lactate originating a peak on MRS and contributing to a further damage of the blood-brain barrier. Animal models demonstrated that, if seizures are prolonged and/ or severe, an energy failure of the $\mathrm{Na}^{+} / \mathrm{K}^{+}$-ATPase pump may occur, with water and $\mathrm{Na}^{+}$influx to the cell (Wang et al., 1996); this mechanism, so as an excessive release of glutamate (Sloviter et al., 1985) and an increased membrane ion permeability (McNamara, 1994), may all contribute to cytotoxic edema observed in some cases, with the corresponding neuronal dysfunction and/ or loss explaining the decreased N-acetylaspartate level and the changes in choline and myoinositol observed in protonic MRS. If this events are interrupted when the auto-regulatory vascular mechanisms still can compensate the high metabolic demands of seizure activity, the neuronal damage is minimized, which probably justifies the reversion of TPMA mainly composed of vasogenic edema (Wieshmann et al., 1997; Silverstein \& Alexander, 1998; Cohen-Gadol et al., 2004; Hong et al., 2004); however, if seizure activity continues, irreversible brain damage may occur, justifying the worse clinical outcome of TPMA mainly composed of cytotoxic edema (Chu et al., 2001; Szabo et al., 2005; Parmar et al., 2006) or in which a lactate peak is revealed on MRS (Fazekas et al., 1995; Lazeyras et al., 2005). 
This cascade of events occurring at the seizure focus certainly contributes to the frequently observed electroclinical-imagiological topographic concordance. In spite of this, a high incidence of focal TPMAs are found even when seizures are triggered/ provoked by systemic factors, are primarily generalized or are associated with diffuse EEG findings, contributing to the broad electroclinical-imagiological spectrum that we described (Canas et al., 2010b). We speculate that this can be attributed to the presence of brain regions intrinsically more susceptible to the TPMA pathophysiological mechanisms or to structural brain lesions that determine a lower seizure threshold. We show that in the presence of these lesions, TPMA are generally located in their periphery (type 2B TPMA), with topographically concordant EEG and clinical findings, suggesting that they may define the probable seizure focus. In the absence of these lesions, we and other authors show that TPMA are generally located in the posterior regions (occipital, parieto-occipital and temporo-occipital) (Chu et al., 2001; Kim et al., 2001, Canas et al., 2010b). The preponderance of TPMA in these regions could be attributed to their lower sympathetic innervation, making them more susceptible to the hyperperfusion induced by seizure activity, in a similar way to the cerebral lesions observed in reversible posterior leukoencephalopathy syndrome, with which TPMA share similar pathophysiological mechanisms and MRI signal abnormalities.

\section{Conclusion}

There is overwhelming evidence, obtained from animal experiments and human case reports, that acute seizures per se can induce brain damage and that MRI is a very powerful tool to its detection. In the clinical context where these MRI seizure-induced lesions generally appear the attending clinicians must be familiar not only with their neuroimaging features, but also with their electroclinical spectrum, allowing an accurate diagnosis. Since these seizure-induced MRI lesions are typically obtained fortuitously, several questions still remain without definite answer, namely which factors predispose only some patients to their development, what determine their different patterns, what are the exact physiopathological mechanisms underlying their formation or if the results of the periictal DWI and MRS studies can be reliable markers of epileptogenesis. To effectively answer these questions there is an urgent need for longitudinal multimodal MRI studies applied systematically in patients presenting with seizures.

\section{Acknowledgments}

We are very grateful to our colleagues that referred patients to our studies, namely Dr. Paula Breia, Dr. Sofia Calado, Dr. Ricardo Pestana and Dr. José Vale; and to the Neuroradiologists that helped in the MRI data review, namely Dr. Paulo Saraiva and Dr. Constança Jordão.

\section{References}

Amato C.; Elia M.; Musumeci S.A.; Bisceglie P. \& Moschini M (2001). Transient MRI abnormalities associated with partial status epilepticus: a case report, European Journal of Radiology, Vol.38, No.1, (April 2001), pp. 50-54 
Bauer, G.; Gotwald, T.; Dobesberger, J.; Embacher, N.; Felber, S.; Bauer, R.; Seppi, K.; Walser, G.; Trinka, E. \& Poewe, W. (2006). Transient and permanent magnetic resonance imaging abnormalities after complex partial status epilepticus, Epilepsy $\mathcal{E}$ Behavior, Vol. 8, No.3, (May 2006), pp. 666-671

Bartolomei, F., Regis, J., Donet, A. \& Gastaut, J.L. (1999). Development of focal chronic epilepsy following focal status epilepticus in adult patients, Neurophysiologie Clinique, Vol.29, No3, (June 1999), pp. 271-276

Briellmann, R.S.; Kalnins, R.M.; Berkovic, S.F. \& Jackson, G.D. (2002). Hippocampal pathology in refractory temporal lobe epilepsy: T2-weighted signal change reflects dentate gliosis, Neurology, Vol.58, No2, (January 2002), pp. 265-271

Briellmann, R.S.; Wellard, R.M. \& Jackson, G.D. (2005). Seizure-associated abnormalities in epilepsy: evidence from MR imaging, Epilepsia, Vol.46, No5, (May 2005), pp. 760766

Canas, N.; Soares, P.; Calado, S.; Pestana, R.; Ribeiro, C. \& Vale, J. (2010a). Pathophysiology and long-term outcome of reversible tumor-like lesions induced by presenting status epilepticus, Journal of Neuroimaging, Vol.20, No.2, (April 2010), pp. 169-174

Canas, N.; Breia, P.; Soares, P.; Saraiva, P.; Calado, S.; Jordão, C. \& Vale, J. (2010b). The electroclinical-imagiological spectrum and long-term outcome of transient periictal MRI abnormalities, Epilepsy Research, Vol.91, No.2-3, (October 2010), pp. 240-252

Castillo, M.; Smith, J.K. \& Kwock L. (2001). Proton MR spectroscopy in patients with acute temporal lobe seizures, AJNR American Journal of Neuroradiology, Vol.22, No1, (January 2001), pp. 152-157

Cha, S. (2006). Update on brain tumor imaging: from anatomy to physiology, AJNR American Journal of Neuroradiology, Vol.27, No3, (May 2006), pp. 475-487

Chu, K.; Kang, D.W.; Kim, J.Y.; Chang, K.H. \& Lee, S.K. (2001). Diffusion-weighted magnetic resonance imaging in nonconvulsive status epilepticus, Archives of Neurology, Vol.58, No6, (June 2001), pp. 993-998

Chan, S.; Chin, S.S.M.; Kartha, K.; Nordli, D.R.; Goodman, R.R.; Pedley, T. \& Hilal, S.K. (1996). Reversible signal abnormalities in the hippocampus and neocortex after prolonged seizures, AJNR American Journal of Neuroradiology, Vol.17, No9, (October 1996), pp. 1725-1731

Cohen-Gadol, A.A.; Britton, J.W.; Worrell, G.A. \& Meyer, F.B. (2004). Transient cortical abnormalities on magnetic resonance imaging after status epilepticus: case report, Surgical Neurology, Vol.61, No5, (May 2004), pp. 479-82

Cole A.J. (2004). Status epilepticus and periictal imaging, Epilepsia, Vol.45, (Suppl. 4), pp. 7277

Di Bonaventura, C.; Bonini, F.; Fattouch, J.; Mari, F.; Petrucci, S.; Carnì, M.; Tinelli, E.; Pantano, P.; Bastianello, S.; Maraviglia, B.; Manfredi, M.; Prencipe, M. \& Giallonardo, A.T. (2009). Diffusion-weighted magnetic resonance imaging in patients with partial status epilepticus, Epilepsia, Vol.50, (Suppl. 1), pp. 45-52

Doherty, C.P.; Cole, A.J.; Grant, P.E.; Fischman, A.; Dooling, E.; Hoch, D.B.; White, T.H. \& Cosgrove, G.R. (2004). Multimodal longitudinal imaging of focal status epilepticus, Canadian Journal of Neurological Sciences, Vol.31, No.2, (May 2004), pp. $276-281$ 
Fabene, P.F.; Marzola, P.; Sbarbati, A. \& Bentivoglio, M. (2003). Magnetic resonance imaging of changes elicited by status epilepticus in the rat brain: diffusionweighted and T2-weighted images, regional blood volume maps, and direct correlation with tissue and cell damage, Neuroimage, Vol.18, No.2, (February 2003), pp. 375-89

Farina, L.; Bergqvist, C.; Zimmerman, R.A.; Haselgrove, J.; Hunter, J.V. \& Bilaniuk, L.T. (2004). Acute diffusion abnormalities in the hippocampus of children with newonset seizures: the development of mesial temporal sclerosis, Neuroradiology, Vol.46, No.4, (April 2004), pp. 251-157

Fazekas, F.; Kapeller, P.; Schmidt, R.; Stollberger, R.; Varosanec, S.; Offenbacher, H.; Fazekas, G. \& Lechner, H. (1995). Magnetic resonance imaging and spectroscopy findings after focal status epilepticus, Epilepsia, Vol.36, No.9, (September 1995), pp. 946-949

Flacke, S.; Wullner, U.; Keller, E.; Hamzei, F. \& Urbach, H. (2000). Reversible changes in echo planar perfusion- and diffusion-weighted MRI in status epilepticus, Neuroradiology, Vol.42, No.2, (February 2000), pp. 92-95

Goulatia, R.K.; Verma, A. ; Mishra, N.K. \& Ahuja, G.K. (1987). Disappearing CT lesions in epilepsy, Epilepsia, Vol.28, No.5, (September-October 1987), pp. 523-527

Goyal, M.K.; Sinha, S.; Ravishankar, S. \& Shivshankar, J.J. (2009). Peri-ictal signal changes in seven patients with status epilepticus: interesting MRI observation, Neuroradiology, Vol.51, No3, (March 2009), pp. 151-61

Hicdonmez, T.; Uktu, U.; Turgut, N.; Cobanoglu, S. \& Birgili, B. (2003). Reversible postictal MRI change mimicking structural lesion, Clinical Neurology and Neurosurgery, Vol.105, No.4, (September 2003), pp. 288-290

Hinchey, J.; Chaves, C.; Appignani, B.; Breen, J.; Pao, L.; Wang, A.; Pessin, M.S.; Lamy, C.; Mas, J.L. \& Caplan, L.R. (1996). A reversible posterior leukoencephalopathy syndrome, New England Journal of Medicine, Vol.334, No.8, (February 22, 1996), pp. 494-500

Hong, K.S.; Cho, Y.J.; Lee, S.K.; Jeong, S.W.; Kim, W.K. \& Oh, E.J. (2004). Diffusion changes suggesting predominant vasogenic oedema during partial status epilepticus, Seizure, Vol.13, No.5, (July 2004), pp. 317-321

Huang, Y.C.; Weng, H.H.; Tsai, Y.T.; Huang, Y.C.; Hsiao, M.C.; Wu, C.Y.; Lin, Y.H.; Hsu, H.L. \& Lee, J.D. (2009). Periictal magnetic resonance imaging in status epilecticus, Epilepsy Research, Vol.86, No.1, (September 2009), pp. 72-81

Juhasz, C.; Scheidl, E. \& Szirmai, I. (1998). Reversible focal MRI abnormalities due to status epilepticus. An EEG, single photon emission computed tomography, transcranial Doppler follow-up study, Electroencephalography and Clinical Neurophysiology, Vol.107, No6, (December 1998), pp. 402-407

Kim, J.-A.; Chung, J.I.; Yoon, P.H., Kim; D.I., Chung, T.-S.; Kim, E.-U. \& Jeong, E.-K. (2001). Transient MR signal changes in patients with generalized tonicoclonic seizure or status epilepticus: periictal diffusion-weighted imaging, AJNR Am J Neuroradiology, Vol.22, No6, (June-July 2001), pp. 1149-1160

Kozak, O.S.; Wijdicks, E.F.; Manno, E.M.; Miley, J.T. \& Rabinstein, A.A. (2007). Status epilepticus as initial manifestation of posterior reversible encephalopathy syndrome, Neurology, Vol.69, No9, (August 2007), pp. 894-897 
Kramer, L.E.; Luders, H.; Lesser, R.P.; Weinstein, M.R.; Dinner, D.S.; Morris, H.H. \& Wyllie, E. (1987). Transient focal abnormalities of neuroimaging studies during focal status epilepticus, Epilepsia, Vol.28, No5, (September-October 1987), pp. 528532

Lansberg, M.G.; O’Brien, M.W.; Norbach, A.M.; Moseley, M.E.; Morrell, M. \& Albers, G.W. (1999). MRI abnormalities associated with partial status epilepticus, Neurology, Vol.52, No5, (March 1999), pp. 1021-1027

Lazeyras, F.; Blanke, O.; Zimine, I.; Delavelle, J.; Perrig, S.H. \& Seeck, M. (2000). MRI, (1)HMRS, and functional MRI during and after prolonged nonconvulsive seizure activity, Neurology, Vol.55, No11, (December 2000), pp. 1677-1682

Masterson, K.; Vargas, M.I. \& Delavelle, J. (2009). Postictal deficit mimicking stroke: role of perfusion CT, Journal of Neuroradiology, Vol.36, No.1, (March 2009), pp. 48-51

McClelland, S.; Libien, J.M.; Chin, S.S.; Adams, D.J.; Resor, S.R.; Chan, S. \& Goodman, R.R. (2005). Unusual findings in brain biopsies of two patients with acute magnetic resonance imaging lesions associated with focal seizures, Epilepsia, Vol.46, No.9, (September 2005), pp. 1495-1501

McNamara, J.O. (1994). Cellular and molecular basis of epilepsy, The Journal of Neurosciences, Vol.14, No6, (June 1994), pp. 3413-3425

Meissner, B.; Kallenberg, K.; Sanchez-Juan, P.; Krasnianski, A.; Heinemann, U.; Varges, D.; Knauth, M. \& Zerr, I. (2008). Isolated cortical signal increase on MRI imaging as a frequent lesion pattern in sporadic Creutzfeldt-Jakob disease, AJNR American Journal of Neuroradiology, Vol.29, No8, (September 2008), pp. 1519-1524

Milligan, T.A.; Zamani, A. \& Bromfield, E. (2009). Frequency and patterns of MRI abnormalities due to status epilepticus, Seizure, Vol.18, No2, (March 2009), pp. 104108

Mueller, S.G.; Kollias, S.S.; Trabesinger, A.H.; Buck, A; Boesiger, P. \& Wieser, H.J. (2001). Proton magnetic resonance spectroscopy characteristics of a focal cortical cortical dysgenesis during status epilepticus and in the interictal state, Seizure, Vol.10, No.7, (October 2001), pp. 518-524

Najm, I; Wang, Y; Hong, S.C; Luders, H.O.; Ng, T.C. \& Comair, Y.G. (1997). Temporal changes in proton MRS metabolites after kainic acid-induced seizures in rat brain, Epilepsia, No38, No1, (January 1997), pp. 87-94

Nakasu, Y.; Nakasy, S.; Morikawa, S.; Uemura, S.; Inubushit, T. \& Handa, J. (1995). Diffusion-weighted MRI in experimental sustained seizures elicited with kainic acid, AJNR American Journal of Neuroradiology, Vol.16, No6, (June-July 1995), pp. 1185-1192

Nixon, J.; Bateman, D. \& Moss, T. (2001). An MRI and neuropathological study of a case of fatal status epilepticus, Seizure, Vol.10, No8, (December 2001), pp. 588-91.

Parmar, H.; Lim, S.H.; Tan, N.C. \& Lim, C.C. (2006). Acute symptomatic seizures and hippocampus damage: DWI and MRS findings, Neurology, Vol.66, No11, (June 2006), pp. 1732-1735

Pohlmann-Eden, B.; Gass, A.; Peters, C.N.; Wennberg, R. \& Blumcke, I. (2004). Evolution of MRI changes and development of bilateral hippocampal sclerosis during long 
lasting generalized status epilepticus, Journal of Neurology, Neurosurgery, and Psychiatry, Vol.75, No6, (June 2004), pp. 898-900.

Provenzale, J.M.; Barboriak, D.P.; VanLandingham, K.; MacFall, J.; Delong, D. \& Lewis, D.V. (2008). Hippocampal MRI signal hyperintensity after febril status epilepticus is predictive of subsequent mesial temporal sclerosis, AJR American Journal of Roentegenology, Vol.190, No.4, (April 2008), pp. 976-983

Raghavendra, S.; Ashalatha, R.; Krishnamoorthy, T.; Kesavadas, C.; Thomas, S.V. \& Radhakrishnan, K. (2007). Reversible periictal MRI abnormalities: clinical correlates and long-term outcome in 12 patients, Epilepsy Research, Vol.73, No1, (January 2007), pp. 129-136

Righini, A.; Pierpaoli, C \& Alger, J.R. (1994). Brain parenchyma ADC alterations associated with experimental complex partial status epilepticus, Magnetic resonance imaging, Vol.12, No6, pp. 865-871

Sammaritano, M; Andermann, F.; Melanson, D.; Pappius, H.M,; Camfield, P; Aicardi, J. \& Sherwin, A. (1985). Prolonged focal cerebral edema associated with partial status epilepticus, Epilepsia, Vol.26, No.4, (July-August 1985), pp. 334-339

Senn, P.; Lovblad, K.O.; Zutter, D.; Bassetti, C.; Zeller, O.; Donati, F. \& Schroth, G. (2003). Changes on diffusion-weighted MRI with focal motor status epilepticus: case report, Neuroradiology, Vol.45, No4, (April 2003), pp. 246-249

Sethi P.K.; Kumar B.R.; Madan V.S. \& Mohan V. (1985). Appearing and Disappearing CT scan abnormalities in seizures, Journal of Neurology, Neurosurgery, and Psychiatry, Vol.49, No.9, (September 1985), pp. 866-869

Silverstein, A.M. \& Alexander, J.A. (1998). Acute postictal cerebral imaging. AJNR American Journal of Neuroradiology, Vol.19, No.8, (September 1998), pp. 14851488

Sloviter R.S. \& Dempster D.W. (1985). "Epileptic" brain damage is replicated qualitatively in the rat hippocampus by central injection of glutamate or aspartate but not by GABA or acetylcholine, Brain Research Bulletin, Vol.15, No1, (January 1985), pp. 3960

Szabo, K.; Poepel , K.; Pohlmann-Eden, B.; Hirsch, J.; Back, T.; Sedlaczek, O.; Hennerici, M. \& Gass, A. (2005). Diffusion-weighted and perfusion MRI demonstrates parenchymal changes in complex partial status epilepticus, Brain, Vol.128, Pt 6, (June 2005), pp. 1369-1376

Theodore, W.H. (1999). Cerebral blood flow and glucose metabolism in human epilepsy, Advances in Neurology, Vol.79, pp. 873-881

Wang, Y.; Majors, A. ; Najm, I. ; Xue, M. ; Comair, Y. ; Modic, M. \& Ng, T.C. (1996). Postictal alteration of sodium content and apparent diffusion coefficient in epileptic rat brain induced by kainic acid, Epilepsia, Vol.37, No10, (October 1996), pp. 1000-1006

Wellard, R.M.; Briellmann, R.S.; Prichard, J.W.; Syngeniotis, A \& Jackson, G.D (2003). Myoinositol abnormalities in temporal lobe epilepsy, Epilepsia, Vol.44, No6, (June 2003), pp. 815-821

Wieshmann U.C.; Symms M.R. \& Shorvon S.D. (1997). Diffusion changes in status epilepticus, Lancet, Vol.350, No9076, (August 16, 1997), pp. 493-494 
Young, G.S.; Geschwind, M.D.; Fischbein, N.J.; Martindale, J.L.; Henry, R.H.; Liu, S.; Wong, S.; Liu, H.; Miller, B.L. \& Dillon, W.P. (2005). Diffusion-weighted and fluidattenuation recovery imaging in Creutzfeldt-Jacob disease: high sensitivity and specificity for diagnosis, AJNR American Journal of Neuroradiology, Vol.26, No6, (June-July 2005), pp. 1551-1562 


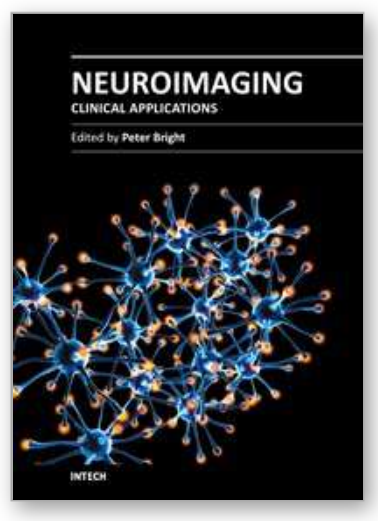

\author{
Neuroimaging - Clinical Applications \\ Edited by Prof. Peter Bright
}

ISBN 978-953-51-0200-7

Hard cover, 576 pages

Publisher InTech

Published online 09, March, 2012

Published in print edition March, 2012

Modern neuroimaging tools allow unprecedented opportunities for understanding brain neuroanatomy and function in health and disease. Each available technique carries with it a particular balance of strengths and limitations, such that converging evidence based on multiple methods provides the most powerful approach for advancing our knowledge in the fields of clinical and cognitive neuroscience. The scope of this book is not to provide a comprehensive overview of methods and their clinical applications but to provide a "snapshot" of current approaches using well established and newly emerging techniques.

\title{
How to reference
}

In order to correctly reference this scholarly work, feel free to copy and paste the following:

Nuno Canas and Pedro Soares (2012). MRI Abnormalities Induced by Seizures, Neuroimaging - Clinical Applications, Prof. Peter Bright (Ed.), ISBN: 978-953-51-0200-7, InTech, Available from:

http://www.intechopen.com/books/neuroimaging-clinical-applications/mri-abnormalities-induced-by-seizures

\section{INTECH}

open science | open minds

\section{InTech Europe}

University Campus STeP Ri

Slavka Krautzeka 83/A

51000 Rijeka, Croatia

Phone: +385 (51) 770447

Fax: +385 (51) 686166

www.intechopen.com

\section{InTech China}

Unit 405, Office Block, Hotel Equatorial Shanghai

No.65, Yan An Road (West), Shanghai, 200040, China

中国上海市延安西路65号上海国际贵都大饭店办公楼 405 单元

Phone: +86-21-62489820

Fax: +86-21-62489821 
(C) 2012 The Author(s). Licensee IntechOpen. This is an open access article distributed under the terms of the Creative Commons Attribution 3.0 License, which permits unrestricted use, distribution, and reproduction in any medium, provided the original work is properly cited. 